\title{
BASIC CALCULATION BASED ON THE DIRECT CONVERSION OF THE HEAT INTO ELECTRICITY FOR IHP
}

\author{
Vladimir Ezhov ${ }^{1}$ \\ Artem Brezhnev ${ }^{2}$ \\ Aleksey Burtsev ${ }^{3}$ \\ Natalia Bredikhina ${ }^{4}$ \\ Aleksandr Burtsev ${ }^{5}$
}

UDK: 620,91

DOI: $10.14415 /$ konferencijaGFS2019.052

Summary. In this work presents a variant of a mathematical model describing the process of direct conversion of heat into electricity to design autonomous power supply of individual heat points, in particular the mixing pump of the heating system of an apartment building. The design and principle of operation of thermoelectric generators for the circulation pump of the heating system of an apartment building.

Keywords: individual heat point, pump, thermoelectricity, thermionic element, coolant, temperature, thermoelectric generator, efficiency, current, voltage, resistance, power.

\section{INTRODUCTION}

The work is devoted to the application of thermoelectricity effect for autonomous power supply of individual heat point (IHP) of the heating system of an apartment building, in particular for the drive of the circulation (mixing) pump.

In modern heat supply systems are widely used individual heating points (IHP).

The scheme of IHP is shown in figure 1.

In work [1] for the solution of a problem of Autonomous power supply IHP it was offered to use effect of thermoelectricity. Based on the study presents a General view of

\footnotetext{
${ }^{1}$ Vladimir. Ezhov, Doctor of Engineering Sciences, Professor, Southwest State University, Faculty of Civil Engineering and Architecture, 50 years of October 94 st., Kursk, Russia, tel: + 747122226 17, e-mail: vlezhov@yandex.ru

${ }^{2}$ Artem Brezhnev, Student, Southwest State University, Faculty of Civil Engineering and Architecture, 50 years of October 94 st.,, Kursk, Russia, tel: + 747122226 17, e-mail: brarvik@icloud.com.

${ }_{3}$ Aleksey Burtsev, Post-Graduate Student, Southwest State University, Faculty of Civil Engineering and Architecture, 50 years of October 94 st.,, Kursk, Russia, 94, tel: + 747122226 17, e-mail: ap_burtsev@mail.ru

${ }^{4}$ Natalia Bredikhina, Vice Dean for Education, Faculty of Civil Engineering and Architecture, Southwest State University, Faculty of Engineering and Architecture, 50 years of October 94 st., Kursk, Russia, tel: + 74712 2225 41, e - mail: natalybredikhin@yandex.ru

${ }^{5}$ Aleksandr Burtsev, Student, Southwest State University, Faculty of Civil Engineering and Architecture, 50 years of October 94 st., Kursk, Russia, tel: + 747122226 17, e-mail: burtsev-999@mail.ru
} 
Савремена достигнућа у грађевинарству 23-24. април 2019. Суботица, СРБИЈА

the thermoelectric generator for the circulation pump with a brief description of the work and the processes occurring in it. [2]

Thermoelectric generator consists of a thermoelectric block (TEB), co-brane of thermoelectric power units, consisting of zigzag rows of thermionic Converter (TEC) are produced from pairs of the segment-cov, made of different metals M1 and M2 (M1chromel, M2-kopel, connected zigzag, the ends of which are flattened and tightly pressed together and located in the heating and cooling zone, near the outer chrome-Ki and the outer surface of the pipe section. [3]

Thermal power plants, in turn, are connected to collectors with the same charges through capacitors, and the thermoelectric unit is equipped with current leads with the same charges connected by electrical wiring to the converter-controller. [4]

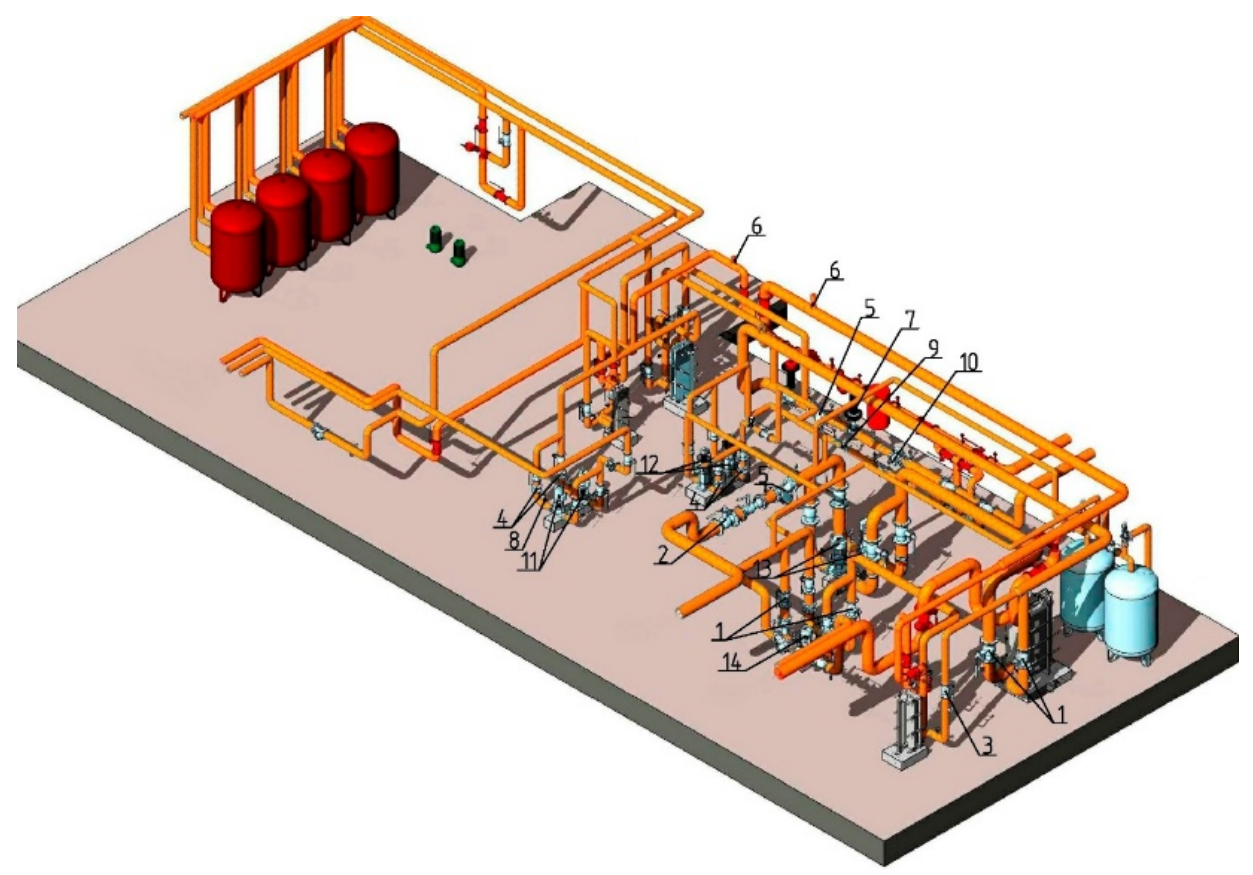

Figure 1. Scheme IHP

1 - ball valve flange DN40; 2-ball valve DN50; 3-ball valve DN40; 4-reverse valve DN40; 5-filter mesh DN40; 6-automatic air outlet-chic DN15; 7 - differential pressure regulator DN20; 8-ball valve DN25; 9-heat exchanger; 10-ultrasound flowmeter; 11-14circulation pumps.

The TEB is mounted on a supply pipeline connected by electrical wiring to an inverter, a battery and a pump motor and consists of two semi-linear housings with longitudinal slits equipped with end rings and longitudinal flanges with fixing holes closing the section of the giving pipeline, with the creation of a gap of width A between the inner surface of the semi-Linders and the outer surface of the section of the pipeline, and longitudinal slits of the semi-cylindrical casings are inserted longitudinal ribs made of a 
Contemporary achievements in civil engineering 23-24. April 2019. Subotica, SERBIA

hydro-resistant dielectric material with a high thickness. thermal conductivity, within which zigzag rows of thermal power plants are placed along their entire length [5] [6]. Thermoelectric generator works as follows. Since the average temperature in the technical basement (warm basement) is $+5^{\circ} \mathrm{C}$, the heat carrier supplied to the IHP from the external heat supply network has a temperature of $+150^{\circ} \mathrm{C}$ in the supply pipeline and $+70^{\circ} \mathrm{C}$ in the return pipeline, between the spas of the TEP .located in the cold and hot zones creates a significant temperature difference $\left(100^{\circ} \mathrm{C}\right.$ or more), which reliably ensures the appearance of co-building thermoelectricity in the TEP and, accordingly, in the TEB, as a result of which the thermoelectric generator begins to produce electricity for the electric motor of the circulation pump and automation means IHP [5].

\section{RESEARCH METHODS}

To solve this problem, an experimental setup was developed and experiments were carried out, on the basis of which a method for calculating the main characteristics of thermoelectric elements was developed.

The heated air from the electric calorifier was used as a coolant (working medium) in the experimental installation. Experiments on the study of heat transfer between the thermoelectric section and the pipeline were carried out in the following sequence. [5]

1. turning on the heater (construction Hairdryer) with a fixed flow rate of heated air, followed by heating until the steady state.

2. installation of calibrated mercury thermometers at the inlet and outlet of the thermoelectric section.

3. record thermometer readings.

4. recording of anemometer readings relative to the velocities at the output of the thermoelectric sections.

The flow temperature was determined as the arithmetic mean value of mercury thermometer readings at the points of entry and exit from the channels of thermoelectric sections.

The main characteristics of thermionic elements made of Chromel (M1) and Copel (M2) are: thermoelectromotive force (TEMF) coefficient $\alpha=12.97 \cdot 10-3 \mathrm{~V} / \mathrm{K}$; quality factor $\mathrm{Z}=$ 2.8 $\cdot 10-3 \mathrm{~K}-1$; electrical conductivity coefficient $\sigma=8 \cdot 104 \mathrm{Ohm}-1 \cdot \mathrm{m}-1$. [5]

The results of the experiment are given in tables 1-2 and figures. 2 and 3.

Table 1. The total thermoelectric voltage, $V$

\begin{tabular}{|c|c|c|c|c|c|c|c|c|c|c|}
\hline $\begin{array}{c}\text { Temperature, } \\
{ }^{\circ} \mathrm{C}\end{array}$ & 80 & 90 & 110 & 120 & 130 & 140 & 150 & 160 & 170 & 180 \\
\hline $\begin{array}{c}\text { The total } \\
\text { voltage, V }\end{array}$ & 0,43 & 0,48 & 0,53 & 0,56 & 0,59 & 0,62 & 0,65 & 0,69 & 0,72 & 0,76 \\
\hline
\end{tabular}

Table 2. The total amperage, $m A$

\begin{tabular}{|c|c|c|c|c|c|c|c|c|c|c|}
\hline $\begin{array}{c}\text { Temperature } \\
,{ }^{\circ} \mathrm{C}\end{array}$ & 80 & 90 & 110 & 120 & 130 & 140 & 150 & 160 & 170 & $\begin{array}{c}18 \\
0\end{array}$ \\
\hline $\begin{array}{c}\text { The total } \\
\text { amperage, } \\
\mathrm{mA}\end{array}$ & $\begin{array}{c}115, \\
2\end{array}$ & 128,0 & $\begin{array}{c}142, \\
3\end{array}$ & $\begin{array}{c}158, \\
1\end{array}$ & $\begin{array}{c}175, \\
6\end{array}$ & $\begin{array}{c}184, \\
9\end{array}$ & $\begin{array}{c}194, \\
6\end{array}$ & $\begin{array}{c}204, \\
9\end{array}$ & $\begin{array}{c}215, \\
7\end{array}$ & $\begin{array}{c}22 \\
7\end{array}$ \\
\hline
\end{tabular}




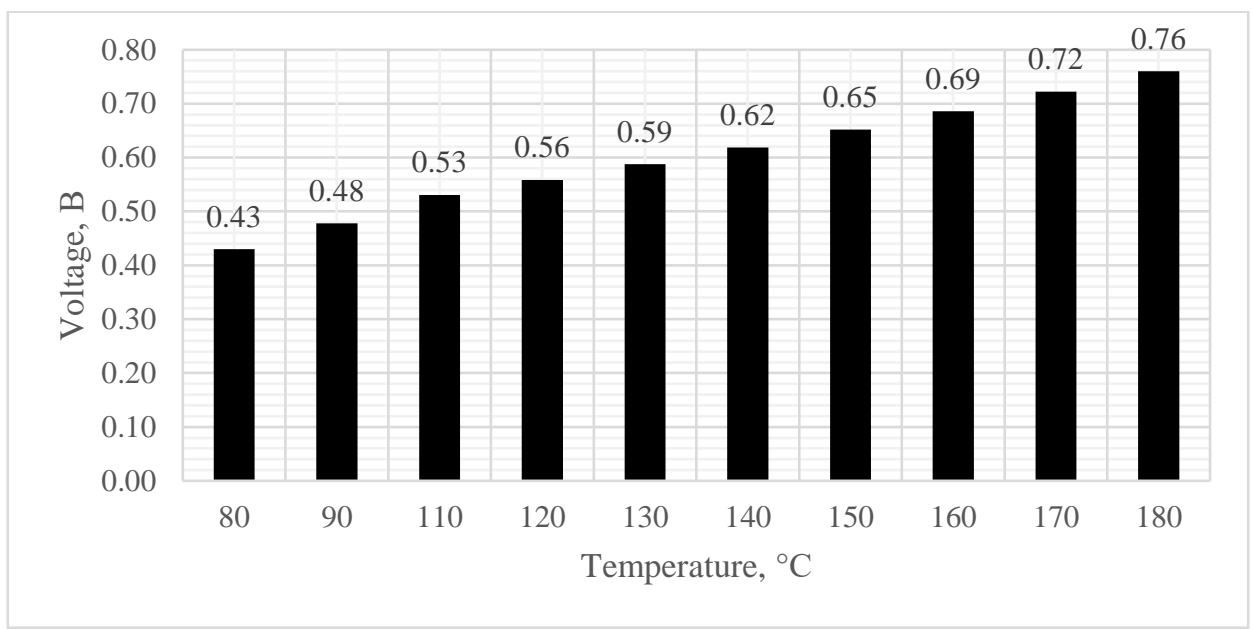

Figure 1. Voltage versus temperature of heated pipe surface curve

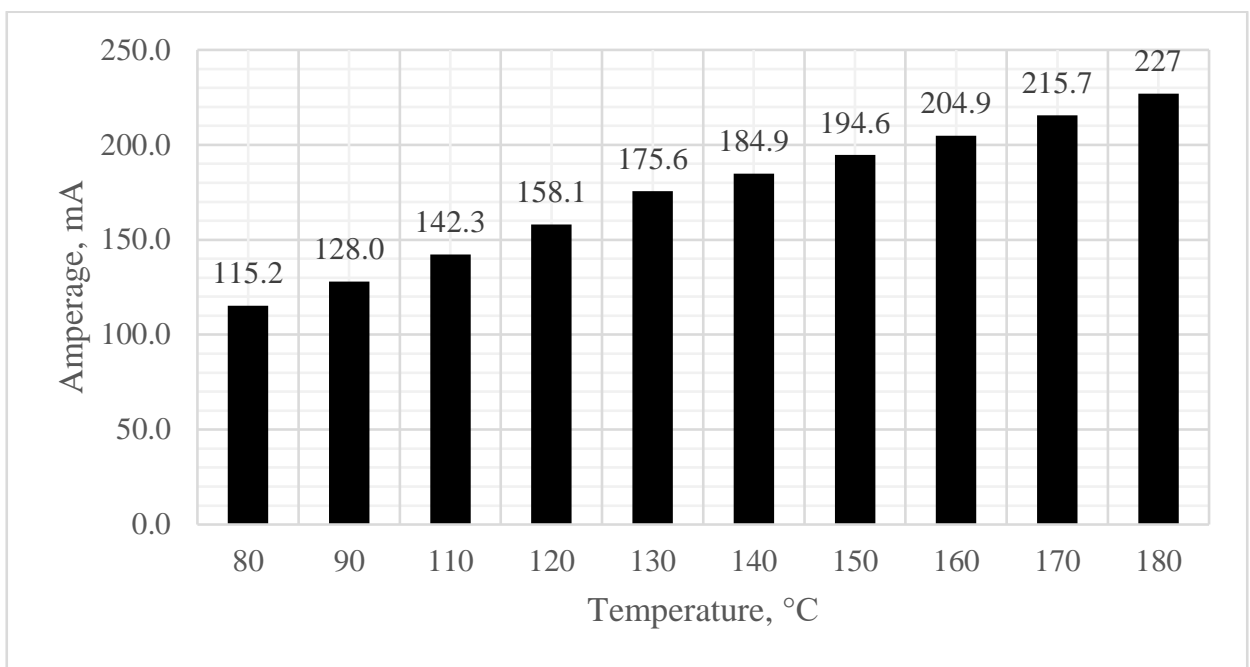

Figure 2. Amperage versus temperature of heated pipe surface curve

\section{DISCUSSION OF RESULTS}

The use of thermoelectricity for the operation of IHP increases the reliability of the heating system. For example, when the electricity is cut off, the circulation pump without autonomous power supply ceases to function and the heating system is switched to manual mode, which dramatically increases the consumption of hot water, which also dramatically reduces its efficiency.

The scope of the considered thermoelectric generator can be quite extensive. It can be used not only in residential but also in public and industrial buildings. 
Contemporary achievements in civil engineering 23-24. April 2019. Subotica, SERBIA

As a result of the conducted experiments, the following data were obtained: the temperature of hot junctions; the temperature of cold junctions; the temperature at the pipe inlet; the temperature at the pipe outlet.

The experimental results show that with increasing hot junctions temperature, voltage and current parameters increase. Determination of the main characteristics of the thermoelectric EMF source:

1. Average heat flow temperature:

$$
\Delta t_{c p}=\frac{t_{1}+t_{2}}{2}
$$

2. Density of air, $\mathrm{kg} / \mathrm{m} 3$ :

$$
p_{h c}\left(\Delta t_{c p}\right)=\frac{P_{h c}}{287,4 \cdot \Delta t_{c p}}
$$

3. Air heat capacity, $\mathrm{J} /(\mathrm{kg} \cdot \mathrm{K})$ :

$$
C p_{h c}\left(\Delta t_{c p}\right)=\left[1,0005+1,1904 \cdot 10^{-4} \cdot\left(\Delta t_{c p}-273\right)\right] \cdot 10^{3}
$$

4. Air thermal conductivity, $\mathrm{W} /(\mathrm{m} \cdot \mathrm{K}))$ :

$$
\lambda_{h c}\left(\Delta t_{c p}\right)=2,44 \cdot 10^{-2} \cdot\left(\frac{\Delta t_{c p}}{273}\right)^{0,82}
$$

5. Air dynamic viscosity coefficient, Pa.s:

$$
\mu_{h c}\left(\Delta t_{c p}\right)=1,717 \cdot 10^{-5} \cdot\left(\frac{\Delta t_{c p}}{273}\right)^{0,683}
$$

6. Air he kinematic viscosity coefficient, $\mathrm{m}^{2} / \mathrm{s}$ :

$$
v_{h c}\left(\Delta t_{c p}\right)=\frac{\mu_{h c}\left(\Delta t_{c p}\right)}{p_{h c}\left(\Delta t_{c p}\right)}
$$

7. Thermal diffusivity coefficient, $\mathrm{m}^{2} / \mathrm{s}$ :

$$
a_{h c}\left(\Delta t_{c p}\right)=\frac{\lambda_{h c}\left(\Delta t_{c p}\right)}{C p_{h c}\left(\Delta t_{c p}\right) \cdot p_{h c}\left(\Delta t_{c p}\right)}
$$

8. Prandtl number:

$$
\operatorname{Pr}_{h c}\left(\Delta t_{c p}\right)=\frac{v_{h c}\left(\Delta t_{c p}\right)}{a_{h c}\left(\Delta t_{c p}\right)}
$$

9. Reynolds criterion:

$$
\operatorname{Re}_{h c}=\frac{w_{h c} \cdot D}{v_{h c}\left(\Delta t_{c p}\right)}
$$

$\operatorname{Re}_{h c}>2320$ is the turbulent flow

10. Nusselt criterion: 
Савремена достигнућа у грађевинарству 23-24. април 2019. Суботица, СРБИЈА

$$
N u_{h c}=0,037 \cdot \operatorname{Re}_{h c L}^{0.8} \cdot \operatorname{Pr}_{h c}^{0.43}
$$

11. Heat transfer coefficient, $\mathrm{W} /(\mathrm{m} 2 \cdot \mathrm{K})$ :

$$
\kappa=\frac{N u_{h c} \cdot \lambda_{h c}}{D}
$$

12. Amount of heat perceived by hot junctions, $\mathrm{W}$ :

$$
Q_{h}=F_{h} \cdot k \cdot\left(t_{1}^{h c}-t_{2}^{h c}\right)
$$

To calculate a thermoelectric generator, it is first necessary to determine the auxiliary thermoelectromotive force coefficient, which depends on the quality factor of the metals used to make a thermoelectric generator and the total resistance of thermoelectric sections.

13. Auxiliary coefficient:

$$
m=\sqrt{1+0,5 Z \cdot\left(t_{1}^{h c}-t_{2}^{c l}\right)}
$$

14. Thermionic converter resistance, Ohm:

$$
R=\frac{\alpha \cdot\left(t_{1}^{h c}-t_{2}^{c l}\right) \cdot N}{I \cdot\left[\sqrt{1+0,5 \cdot Z \cdot\left(t_{1}^{h c}+t_{2}^{c l}\right)-1}\right]}
$$

15. Thermocouple resistance, Ohm:

$$
R_{0}=\frac{R}{N}
$$

16. Electrical power delivered to the external circuit, $\mathrm{W}$ :

$$
Q=\frac{(2 \cdot N \cdot \alpha)^{2} \cdot\left(t_{1}^{h c}-t_{2}^{c l}\right)}{R} \cdot \frac{m}{(m+1)^{2}}
$$

17. Efficiency, \%:

$$
\eta=\frac{Q}{Q_{h}}
$$

\section{CONCLUSIONS}

The main conclusions can be considered:

1. the design of an autonomous EMF source for power supply of IHP is proposed;

2. the design of the power supply allows you to adjust the current parameters depending on the flow rate and temperature of the pumped liquid;

3. experience-based data on the laboratory installation for thermoelectricity generation are presented;

4. the calculated mathematical model of thermoelectric generator operation is created. 
Contemporary achievements in civil engineering 23-24. April 2019. Subotica, SERBIA

\section{REFERENCES}

[1] T. V. M. Yezhov V.S., Yemelianov S.G., Semicheva N.E., Berezin S.V., Burtsev A.P., "Direct heat energy conversion into electrical energy: an experimental study,” J. Appl. Eng. Sci., vol. 4, no. 13, pp. 265-270, 2015.

[2] B. A. P. Ezhov V.S., Semicheva N.E., Berezin S.V., Amelin V.N, "Investigation of technical characteristics of thermoelectric add-on for pressure jet burners," $J$. Appl. Eng. Sci., vol. 4, pp. 461-464, 2016.

[3] R. Schmechel, R. Chavez, P. Rogl, G. Schierning, B. Balke, and G. Rogl, "Concepts for medium-high to high temperature thermoelectric heat-toelectricity conversion: a review of selected materials and basic considerations of module design,” Transl. Mater. Res., vol. 2, no. 2, p. 025001, 2015.

[4] K. Bartholomé et al., "Thermoelectric modules based on half-heusler materials produced in large quantities,” J. Electron. Mater., vol. 43, no. 6, pp. 1775-1781, 2014.

[5] V. S. Ezhov et al., "Independant power supply source for the station of cathodic protection of pipelines against corrosion,” J. Appl. Eng. Sci., vol. 15, no. 4, pp. 501-504, 2017.

[6] V. Ezhov, N. Semicheva, S. Berezin, V. Amelin, and A. Burtsev, "Investigation of technical characteristics of thermoelectric add-on for pressure jet burners," $J$. Appl. Eng. Sci., vol. 14, no. 4, pp. 461-464, 2016. 